\title{
Current Knowledge and Potential Applications of Ionic Liquids in the Petroleum Industry
}

\author{
Murillo-Hernández José-Alberto ${ }^{1}$ and Aburto Jorge ${ }^{2}$ \\ ${ }^{1}$ Universidad Nacional Autónoma de México, \\ 2Instituto Mexicano del Petróleo \\ Mexico
}

\section{Introduction}

The modern petroleum industry is confronting many challenges throughout the chain value, since the production and refining of crude oil to the manufacture of high-value petrochemical products. Conventional light and middle crude oil production reached a maximum and tends to decline. Also, some producing countries are dealing with heaviest and higher content of pollutants (sulfur, nitrogen and metals) crude oils, which are being produced in countries like Canada, China, Mexico, Venezuela and the USA. Such heavy and extra heavy crude oils (HCOs) are more difficult to produce, transport, refine and convert to useful petrochemicals. Sometimes, conventional technologies may be applied but in most cases, new technologies are needed in order to allow economical HCOs production, transportation through pipelines, avoiding pressure drops, pipeline clogging and production stops due to asphaltene and paraffin aggregation and precipitation. Also, the higher content of heteroatoms in HCOs makes them more difficult to refine because of mainly catalyst deactivation that decreases the efficiency of processes like desulfurization, denitrogenation and demetallization. Moreover, the crude oil composition largely varies from one oil field to another among deposits along the countries. Heavy and extra-heavy oil are characterized by an API gravity between $20<\mathrm{API}<10$ and $\mathrm{API} \leq 10$, respectively. The latter oils present a specific gravity near or above $1.0 \mathrm{~g} / \mathrm{cm}^{3}$, i.e. they are as heavier or more than water, making crude oil dehydration, for example, very difficult to reach before refining. Therefore, the modern petroleum industry is facing several problems in petroleum production and refining.

In last years, ionic liquids (ILs) have attracted the attention because of their properties and versatility of potential application in the petroleum industry. ILs may be use to augment the flowability of viscous and bituminous HCOs that could augment oil production and transportation, inhibit the aggregation of asphaltenes and paraffins, and diminish the deactivation of refining catalyst by removing heteroatoms and coke from the fuel and catalyst's surface. Because of the technological, environmental and economical impacts, this work reviews the current knowledge and potential application of ILs in petroleum industry.

\section{Petroleum production}

According to Speight (1999), crude oil is a mixture of gaseous, liquid and solid hydrocarbon that occur in porous rock deposits called reservoirs and that contains variable quantities of 
nitrogen-, oxygen-, and sulphur-containing compounds as well as traces of metals. Such complex mixture may be separated in four constituent fractions: saturates $(S)$, aromatics (A), resins (R) and asphaltenes (A); known as SARA fractions (Table 1). Since these major crude oil fractions are obtained by consecutive separation methods (Figure 1), it is difficult to base

\begin{tabular}{lcccccc} 
& & Mexico & & Canada & $\begin{array}{c}\text { Venezue } \\
\text { la }\end{array}$ & China \\
\hline Parameter & Medium & Heavy & $\begin{array}{c}\text { Extra- } \\
\text { heavy }\end{array}$ & Bitumen & $\begin{array}{c}\text { Extra- } \\
\text { heavy }\end{array}$ & $\begin{array}{c}\text { Extra- } \\
\text { heavy }\end{array}$ \\
\hline $\begin{array}{l}\text { API gravity } \\
\text { Molecular weight }\end{array}$ & 21.3 & 11.9 & 9.2 & 5.9 & 10 & 7.2 \\
(g/mol) & 314.8 & 486 & 507.8 & $\mathrm{ND}$ & $\mathrm{ND}$ & $\mathrm{ND}$ \\
Sulfur content (\%) & 3.4 & 5.0 & 4.8 & 4.9 & 3.2 & $\mathrm{ND}$ \\
Water content (\%) & 1.80 & 0.05 & $<0.05$ & 0.0 & $\mathrm{ND}$ & $\mathrm{ND}$ \\
Carbon residue (\%) & 0.0 & 0.0 & 0.0 & 18.5 & $\mathrm{ND}$ & $\mathrm{ND}$ \\
\hline SARA analysis (\%) & & & & & & \\
\hline Saturates & 26.5 & 7.9 & 15.0 & 15.1 & 11.0 & 36.3 \\
$\begin{array}{l}\text { Aromatics } \\
\text { Resins }\end{array}$ & 14.7 & 5.3 & 19.1 & $\mathrm{ND}$ & 19.0 & 23.6 \\
Asphaltenes & 47.6 & 70.9 & 46.8 & 34.1 & 54.0 & 32.7 \\
\hline
\end{tabular}

Table 1. Properties and composition of some medium, heavy and extra-heavy crude oils from Canada, China, Mexico and Venezuela. Adapted from (Isea, 1987; Speight, 1999; Zhang, 2005; Murillo-Hernández, 2009; Castro, 2009; Riveros, 2006; Strausz, 2010). ND: not determined.

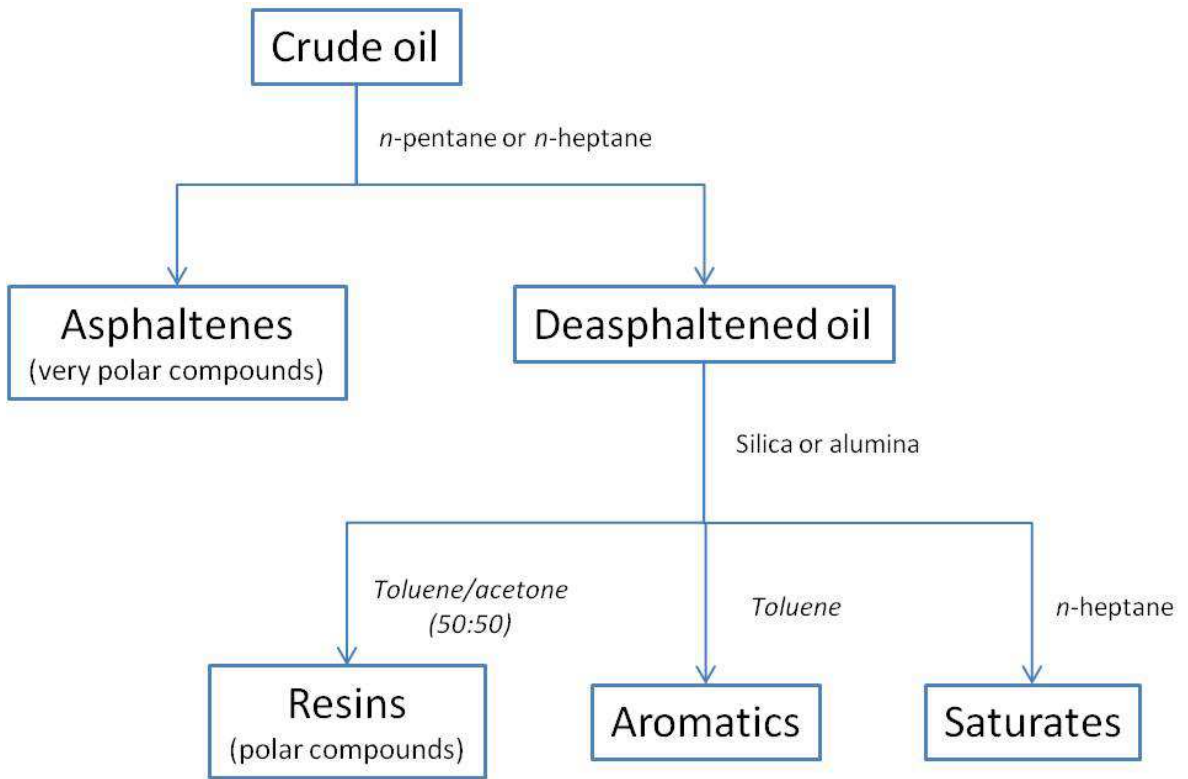

Fig. 1. Simplified fractionation method of crude oil. 
such fractions on chemical or structure features. Nevertheless, saturates are found in the nheptane eluent and are composed by straight or branched acyclic (also called paraffins) and cyclic saturated hydrocarbons $\left(19 \leq C_{n} \leq 40\right)$; aromatics are found in the toluene eluent and we can consider them as hydrocarbons containing one or more aromatic ring systems substituted by other aromatic rings or saturated hydrocarbons. Resins or polar compounds are desorbed with a toluene/acetone eluent; while asphaltenes are the fraction insoluble in $n$-pentane or $n$-heptane and are considered polynuclear aromatic systems and the more polar fraction of crude oil (Speight, 1999; Speight, 2004a; ASTM, 2007; Strausz et al., 2010). Hence, each SARA fraction corresponds to an enormous group of compounds, quantifed in the laboratory by solvent precipitation, adsorption and solvent extraction; that contributes to the physicochemical properties of the crude oil like API gravity and viscosity. Heavy and extra-heavy crude oils are mainly characterized by an API gravity between $20<\mathrm{API}<10$ and $\mathrm{API} \leq 10$, respectively; and high viscosities $\left(>10-10^{4} \mathrm{~Pa}^{*} \mathrm{~s}\right)$. Such crude oils sites are regionally found in countries like Canada, China, Mexico, Venezuela and USA (Figure 2).
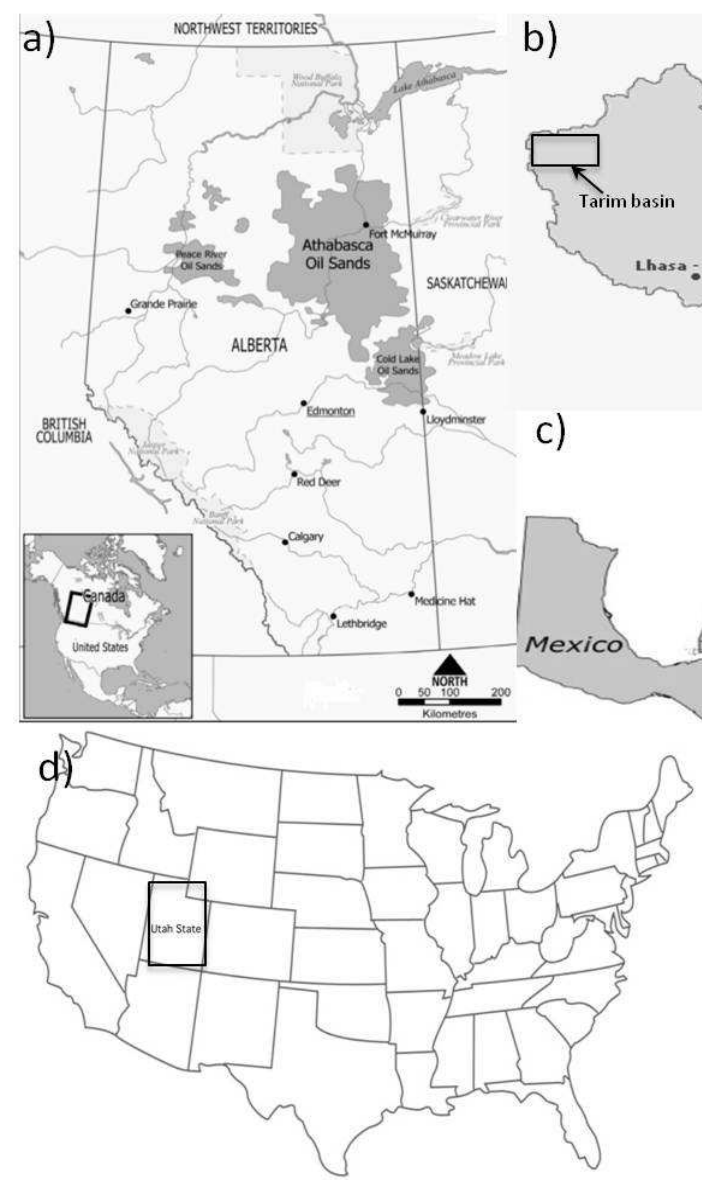

Fig. 2. Production sites of heavy and extra-heavy oil in the world: a) Canada, b) China, c) Mexico, d) USA and e) Venezuela.
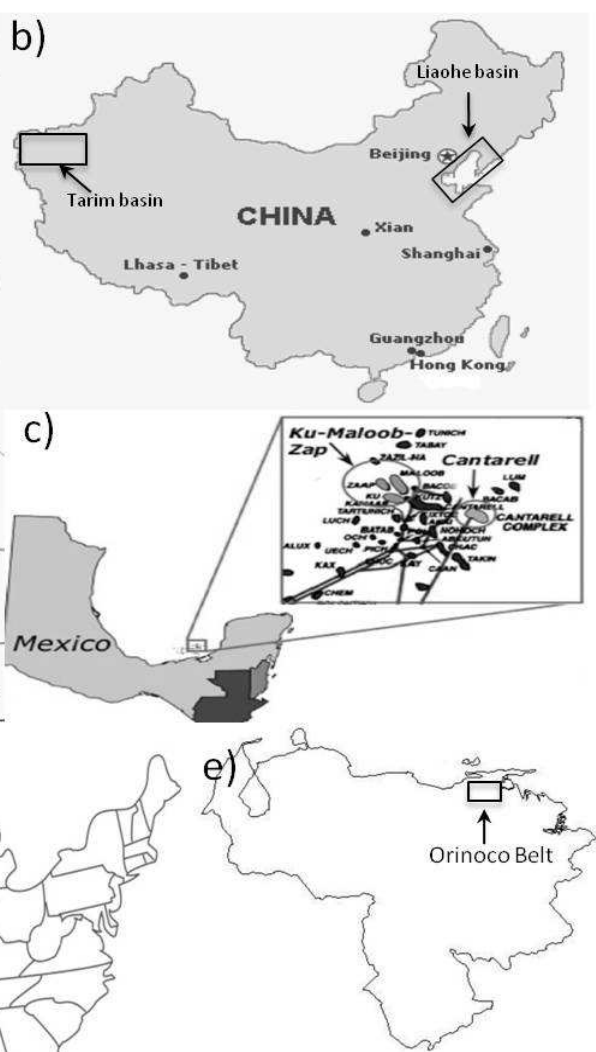
Heavy and extra-heavy crude oil production from reservoirs and transport to terminals presents several problems associated with oil production, precipitation of asphaltenes, resins and paraffins (saturated hydrocarbons with straight or branched chains), petroleum's high viscosity and low flowability, formation of water-in-oil (W/O) emulsions, corrosion of production and pipeline infrastructure and decaying of petroleum production. A recent work deals with the evaluation of extra-heavy oil production from Canadian and Utah tar sands using ILs (Painter et al., 2010a, Painter et al., 2010b). They could recover till $90 \%$ yield of extra-heavy oil from Canadian tar sands using common ILs like $[\mathrm{Bmim}]^{+}\left[\mathrm{CF}_{3} \mathrm{SO}_{3}\right]^{-}$and $[\mathrm{Bmmim}]^{+}\left[\mathrm{BF}_{4}\right]^{-}$and ILs could be recycled till 5 times without noticeable loss of efficiency. Nevertheless, Utah tar sand needed the use of consecutive additions of toluene as cosolvent apparently because of over saturation. These are the first reports concerning the production of crude oil using ILs and some advantages are the elimination or reduction of water use during oil extraction, good separation of sand and clay from crude oil, reduction of corrosion issues, and ease separation of ILs from tar sand. Although, this is only an exploratory study that needs more work in order to address a number of issues like the choice of IL, crude oil/IL ratio, use of cosolvents, the kinetics of the separation process, costs, and environmental concerns.

\subsection{Deposition of asphaltenes and paraffins}

The stability of asphaltenes in crude oil is proposed to be due to the presence of some polar substances, resins among them, present in crude oil (Chang \& Fogler, 1994). Goual and Firoozabadi (2002) suggested that both asphaltene and resins molecules are polar and associated as micelles, thanks to the positively charged asphaltenes that would be dispersed in the crude oil by negatively charged resins through electron donor acceptors and hydrogen bonding interactions (González et al., 2003). In fact, asphaltenes and resins coexist in a petroleum fluid and may be found in the form of monomers or associated as micelles. In the latter form, the micellar core is formed by the self association of asphaltene molecules with adsorbed resins at the surface to form a shell that also contains an oil fraction (Figure 3). Then, resins may be essential in asphaltene aggregation and stabilization because they attach to asphaltene micelles through their polar head and hence stretch their aliphatic groups outward to form a steric-stabilization layer surrounding asphaltene molecules. The formation and properties of such micelles is governed by the relative concentration of asphaltenes and resins. It seems that when resins are desorbed from or exceeds a critical concentration at the micellar core surface, they give rise to the asphaltene phase that aggregates and eventually precipitates (Pacheco-Sánchez et al., 2004; García-Cruz et al., 2005; Pereira et al., 2007). Hence, resins are proposed as the natural dispersants of asphaltenes in crude oil but there some controversy about the aggregation mechanisms (Sedghi \& Goual, 2010).

Asphaltene and paraffins aggregation and deposition into the rock reservoir, through the production well clogging pumps, valves and pipes represents a very serious and constant problem in oil production and transport with an enormous economic impact. This is because asphaltene or paraffin aggregation and solid formation may occur in reservoirs and oil wells, provoking the formation of an extremely dense phase that reduces oil extraction and in many cases completely stops oil production. Also, asphaltene and paraffins deposition occurs in destabilized crude oil blends and during oil storage (Thanh et al., 1999; Speight, 1999; Srivastava et al., 2002; Speight 2004a, Speight 2004b; Murgich et al., 2001; Murgichet al., 1998; Mansoori, 1997; Buenrostro-González et al., 2001; Carbognani et al., 1999; Oh \& 

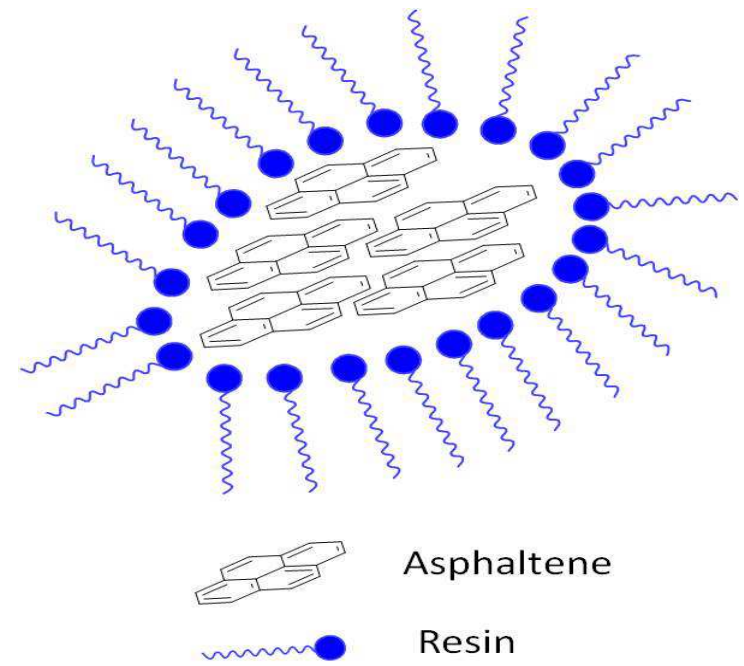

Fig. 3. Schematic representation of an asphaltene-resin micelle presents in crude oil.

Deo, 2002; Leon et al., 2000; Visintin et al., 2008). The factors influencing asphaltene and paraffin aggregation are ruled by the equilibrium disturbance of crude oil's original composition, presence of trapped water in the reservoir (also called formation water), temperature diminution that favors aggregation as well as their chemical modification in the reservoir (Table 2). For example, the stability of asphaltenes in crude oil is influenced by the composition, temperature, and pressure of crude oil; asphaltenes can be destabilized as the pressure approaches toward the bubble point of crude oil (where solubilised gas starts to evaporate from the oil phase). The understanding of these factors and aggregation phenomena are crucial to find practical and effective solutions to the oil industry. It is of commonly use, the addition of aromatic solvents like xylene or cosolvents like amines or sulfonic acid derivatives. Although, the empirical approach may cause damage to the rock reservoir (also called formation damage), increase asphaltene aggregation as well as useless, costly and time-consuming procedures that may compromise oil production. Recently, we have reviewed several conventional and emerging technologies to allow crude oil flowing and transportation by pipeline which somehow reduce asphaltene and paraffin aggregation and precipitation (Aburto et al., 2009).

On the subject of ILs application to the asphaltene problems, Liu et al. (2005) studied the dissolution of asphaltenes from Shengli crude oil in ILs. They mixed the isolated asphaltene sample with ILs and heated them up to different temperatures $\left(50,80,135\right.$ and $\left.150^{\circ} \mathrm{C}\right)$ in order to determine their solubility. It was observed that the ILs based on isoquinolinium cation can dissolve asphaltenes better than pyridinium and imidazolium cations. Also, the ILs capacity to dissolve asphaltenes decreases with the major substitution of the alkyl chain of ILs. The effect of the anion over the capacity to dissolve asphaltenes was found to augment with minor molar volumes, i.e. the anion [Cl]- showed the better dissolution of ILs within a range of $20-27 \%$ between 80 to $150^{\circ} \mathrm{C}$. Authors proposed that asphaltene dissolution occurs by ILs breaking of asphaltene associations, mainly hydrogen bonds. Now, the dissolution approach to solve asphaltene aggregation and deposition should be carefully studied before practical application since tested ILs are poor soluble in water 
Fractions

\begin{tabular}{|c|c|}
\hline Asphaltenes & $\begin{array}{l}\text { - Disturbance of the pressure-temperature reservoir equilibrium } \\
\text { that alters the natural abundances of crude oil fractions, i.e. gas } \\
\text { separation from crude oil in primary recovery, during gas } \\
\text { injection into reservoir in secondary recovery or through } \\
\text { polymer injection, by instance, into the reservoir during tertiary } \\
\text { recovery, also called enhanced oil recovery (EOR). } \\
\text { - Injection of light petroleum fractions or light to medium crude } \\
\text { oils to the reservoir to facilitate production of heavy and extra- } \\
\text { heavy crude oils. } \\
\text { Chemical modification of fractions during recovery processes, } \\
\text { especially through thermal recovery processes. }\end{array}$ \\
\hline Paraffins & $\begin{array}{l}\text { - Ascension of crude oil from the reservoir through the } \\
\text { production well and during pipeline transport to the terminal } \\
\text { may cause heat loss and paraffin crystallization and } \\
\text { sedimentation. } \\
\text { - Presence of water in the reservoir that favors the formation of a } \\
\text { paraffin shell around water drops. } \\
\text { - Blending two or more crude oils }\end{array}$ \\
\hline
\end{tabular}

Table 2. Factors influencing asphaltene and paraffins agglomeration and solid formation. injection and effect on real crude oil sample should be essayed to get more insights about ILs functionality.

Hence, $\mathrm{Hu} \& \mathrm{Guo}(2005)$ studied the effect of IL sand amphiphile molecules in the inhibition of asphaltene precipitation in simulated $\mathrm{CO}_{2}$-injected reservoir oil. The $\mathrm{CO}_{2}$ flooding is a promising enhanced oil recovery technique for reservoirs but asphaltene or paraffin (Hu et al., 2004) precipitation and subsequent clogging of the rock formation as well as production and transport equipment may be an important disadvantage (Figure 4). The experiment was conducted in a high-pressure cell where the crude oil and the ILs were mixed and $\mathrm{CO}_{2}$ was injected as an asphaltene precipitation agent. It was found that inhibition abilities of ILs like $\mathrm{C}_{n}$ phol and resins such as $\mathrm{C}_{n}$ bsa, and $\mathrm{C}_{n}$ bsNa increase with elongating the alkyl chain length between $2 \leq n<8$ and then remain constant for $n \geq 8$. Nevertheless, the [ $\mathrm{C}_{n}$ py][Cl] series display an inverse trend and inhibition of asphaltene precipitation auments from $n=12$ to $n=4$; and $[\mathrm{C} 4 \mathrm{iql}][\mathrm{Cl}]$ revealed as the better inhibitor with the minor charge density on the cation. Something important about this work is that the ability of ILs and amphiphiles to inhibit asphaltene deposition varies from one kind of crude oil to another. Indeed, Xinmin, Shengli and $\mathrm{MuH}$ are Chinese medium crude oils with an asphaltene content between 1.5 to $3.5 \%(\mathrm{Hu}, 2005)$. The Xinmin oil has more asphaltenes and a larger specific gravity $(0.9206$ $\mathrm{g} / \mathrm{cm}^{3}$ at $20^{\circ} \mathrm{C}$ ) than the other two tested oils with similar properties. Non IL could completely inhibit asphaltene precipitation only the benzene sulfonic amphiphiles, but at a high concentration of $4 \% \mathrm{w} / \mathrm{w}$. Such quantity of an additive to prevent or correct asphaltene deposition into the reservoir or even at a storage tank may cause important operational problems that should be carefully planned: ILs storage, solvent storage and mixing with ILs, ILs injection to the well or tank, ILs effect on water separation, corrosion and crude oil refining. 


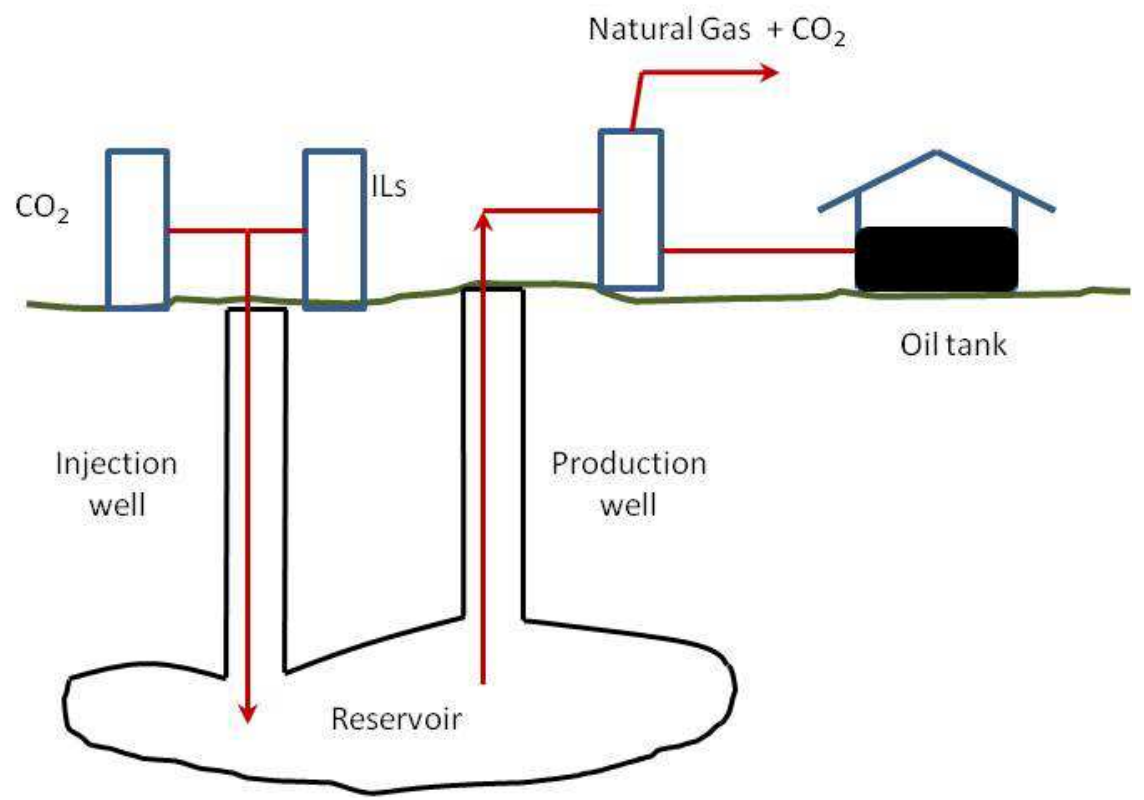

Fig. 4. Scheme of $\mathrm{CO}_{2}$ flooding and hypothetical ILs utilization for enhanced oil recovery with minor asphaltene precipitation and deposition issues.

Although ILs may be potential asphaltene deposition inhibitors, there still many basic questions that should be answered first prior to industrial essays. An important basic and applicative question is related to IL-IL interactions, ILs dosification and how polar asphaltenes or asphaltene-resin complex interact with ILs. Hence, imidazolium- and pyridinium-based ILs presented a critical aggregation concentration (CAC) in solution, i.e. these ILs aggregate at certain concentration around the molecules of a Mexican heavy crude oil sample (MHCOs) used as fluorescent probe (Figure 5; Murillo-Hernández et al., 2009). The IL molecules surround and clog the fluorophore molecules of MHCOs, which sense a more apolar microenvironment at the $\mathrm{CAC}$ value due to the blue shifting of the spectra of the MHCOs at increasing IL concentration. Such observation can be explained if we consider that ILs may interact through their apolar tail with resin-stabilized asphaltenes aggregates in the MHCOs, resulting in an increasing apolar microenvironment around asphaltene molecules (Figure 6a). The CAC value show then the critical concentration of ILs at which a miscelle-like aggregate is formed and varies from 10 to $50 \mathrm{ppm}$ for studied ILs. The resinstabilized asphaltenes may be further stabilized by this ILs shell and limit asphalteneasphaltene interaction, aggregation and precipitation. Nevertheless, we must also consider the IL-IL interaction since it forms the outer shell and may favour the formation of loosy or tighty aggregates (Figure 6b). It appears clear here that we need ILs that strongly interact with asphaltenes or resin-asphaltene aggregates in order to stabilize them but slightly or nothing affinity with themselves. The ILs with smaller CAC values should then have a structure that facilitates stronger IL-IL interaction that other ILs with larger CAC values, i.e. $[\mathrm{Emim}]^{+}[\mathrm{Br}]^{-}$with an ethyl substitution forms at lower concentration a tight micelle-like structure while $[\mathrm{Bmim}]^{+}\left[\mathrm{AlCl}_{4}\right]^{-}$with a butyl group and a larger anion requires 5 times more 


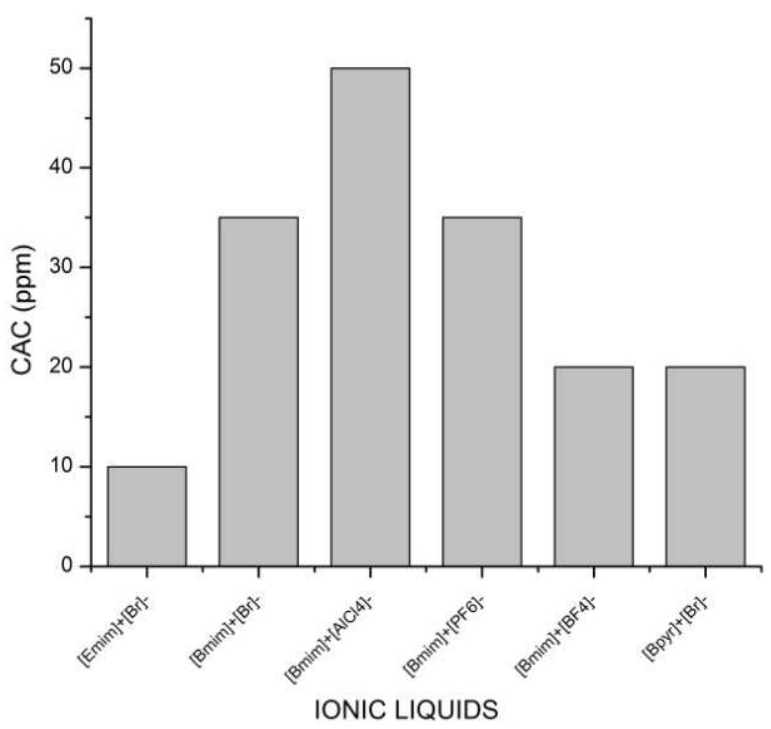

Fig. 5. Values of the critical aggregation concentration of various imidazolium- and pyridinium-based ILs.

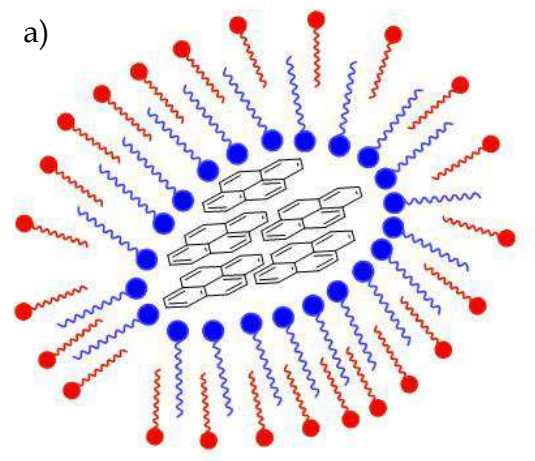

b)
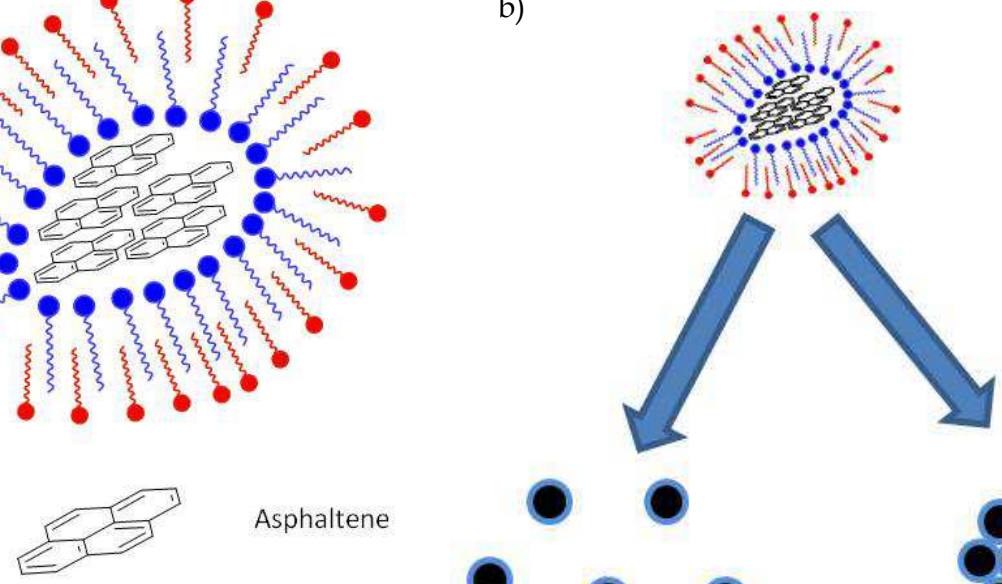

Asphaltene

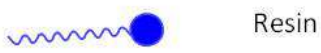

Ionic liquid

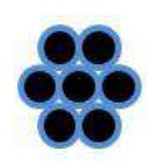

Tight aggregates

Fig. 6. Proposed scheme of a) the interaction of ILs with resin-asphaltene aggregates and b) further asphaltene aggregates stabilization with ILs. 
molecules to aggregate. Additional information about ILs that must be generated is the dissociation constants $\left(K_{d}\right.$, Equation 1), and the surface and interfacial tension values of ILs solutions that may give some insights about their dispersion capacity of crude oils, specifically asphaltenes and/or paraffins.

$$
I L+I L \stackrel{K_{d}}{\longleftrightarrow} I L_{n}
$$

We study also the aggregation of a MHCOs by spectrofluorometry and found that it occurs at a predominant polar microenvironment either by incrementing the crude oil concentration or the n-heptane volume (Murillo-Hernández et al., 2009). The addition of an IL modifies such aggregation and displaces it to larger MHCOs concentration or n-heptane volume. Here, ILs set a polar microenvironment around MHCOs aggregates, which stabilized them against further aggregation and precipitation (Figure 6b). The better performance of ILs as inhibitors or stabilizers of asphaltene aggregation was found with those comporting a complex anion, a pyridinium ring, or a shorter alkyl substitution on the cation. Such ILs present also the higher values of the calculated electronic properties. Another important finding is that ILs set a polar microenvironment around MHCOs molecules, which allows MHCOs-ILs-MHCOs interactions, limits MHCOs aggregation, and shifts the aggregation to a larger MHCOs concentration (Figure 7); i.e. ILs like $[\mathrm{Bmim}]^{+}\left[\mathrm{BF}_{4}\right]^{-}$and $[\mathrm{Bmim}]^{+}\left[\mathrm{AlCl}_{4}\right]^{-}$shift the MHCOs aggregation from initial 60 to 180 and $330 \mathrm{ppm}$, respectively. Here, coverage of MHCOs molecules by ILs should be homogenous (mono or multilayer) or a more specific IL-stabilized MHCOs interaction should exist that prevents asphaltene aggregation with poor IL-IL interactions. On the other hand, ILs that not or poorly shift the MHCOs aggregation $\left([\mathrm{Bmim}]^{+}\left[\mathrm{PF}_{6}\right]^{-}\right.$or $\left.[\mathrm{Bmim}]^{+}\left[\mathrm{PF}_{6}\right]^{-}\right)$may be explained in terms of a heterogeneous or incomplete coverage of MHCOs molecules, to more specific MHCOs-MHCOs interactions that displace MHCOs-IL interaction or to strong IL-IL interactions that favour asphaltene aggregation. $\mathrm{Hu}$ \& Guo (2005) found that ILs with $\left[\mathrm{BF}_{4}\right]^{-}$and $\left[\mathrm{PF}_{6}\right]^{-}$anions have less ability to inhibit asphaltene precipitation because these anions are weakly complexing anions and thus are not expected to break intramolecular associations of asphaltenes because of their low charge densities and symmetrical shapes. But, $[\mathrm{Cl}]^{-}$anion is a better inihibitor because it possesses the ability to undergo acid-base interactions with asphaltenes, breaking intramolecular interactions and subsequently binding itself with asphaltenes. ILs with a $[\mathrm{Br}]^{-}$anion have a better MHCOs aggregation shifting when compared to $\left[\mathrm{PF}_{6}\right]^{-}$but less than $\left[\mathrm{BF}_{4}\right]^{-}$(Figure 7 ). It seems then that several factors affect asphaltene stabilization/destabilization, and that general rules do not apply to ILs utilization in crude oils. Further research must take into consideration factors like the chemical properties of asphaltenes and other SARA fractions present in a specific kind of crude oil, spatial variations of properties of the same crude oil, basic and acid sites in asphaltenes and ILs structure (Boukherissa et al., 2009), relative polarity at aggregation point of crude oil and isolated asphaltenes, etc. More insights about asphaltene aggregation and precipitation are needed in order to understand the ruling adsorption mechanisms among asphaltenes, asphaltene-resin aggregates and ILs. Such knowledge may be acquired through experimental adsorption isotherms and the estimation of affinity constants and adsorption capacities.

In regard to paraffin crystallization and deposition, the formation of wax crystals occurs as a consequence of temperature diminution of crude oil. The solids formed are mainly mixtures containing n-paraffins ranging from $\mathrm{C} 20$ to $\mathrm{C} 40$ and higher. However, the deposition of branched chain paraffins may drag also naphthenic acids, aromatics compounds as well as 
asphaltenes and resins and the mechanisms are quite complex and poorly understood (Oliveria et al., 2007). The main factors determining organic deposition are petroleum composition, the thermohydraulic profile along the production pipelines and temperature changes among the reservoir, production well, transportation pipelines and storage tanks. The paraffin precipitation also causes a change in the crude oil flow behavior from Newtonian to non-Newtonian, augmenting viscosity and pressure to pump it along the pipelines. Hence, the lowest temperature at which movement of the crude oil specimen is observed under the conditions of the test is called the pour point temperature and corresponds to a phase transition in which the oil goes from a fluid dispersion to a wax-oil gel (ASTM D 5853, 2009). The use of scrapers, hot oil treatments and solvents ease the operation; but the application of remedial measures becomes prohibitive economically in extremely deep production, offshore drilling and ocean floor completions. Certain chemical products are used as flow improvers, crystal modifiers, and pour point reducing agents that diminish apparent viscosity and the pour point of oils having a tendency to wax crystallization through various not still well defined mechanisms, but there is evidence that asphaltenes and naphthenic acids may interfere or favour paraffin crystallization (Oliveira et al., 2007). Despite that mechanisms of paraffin inhibitors are still under discussion, the pour point depressant agent acts most likely by crystal modification and/or dispersion, while asphaltenes probably adsorb to a greater degree to the pipe wall, preventing strong adhesion by the wax (Mendell \& Jessen, 1970). Here, ILs could also serve as pour point reducing agents, but the issue is still open and for example, (liquid + liquid) equilibrium data for complex systems are needed in order to approach the technical and economical feasibility of ILs as paraffin inhibitor or extractor (Hansmeier et al., 2010).

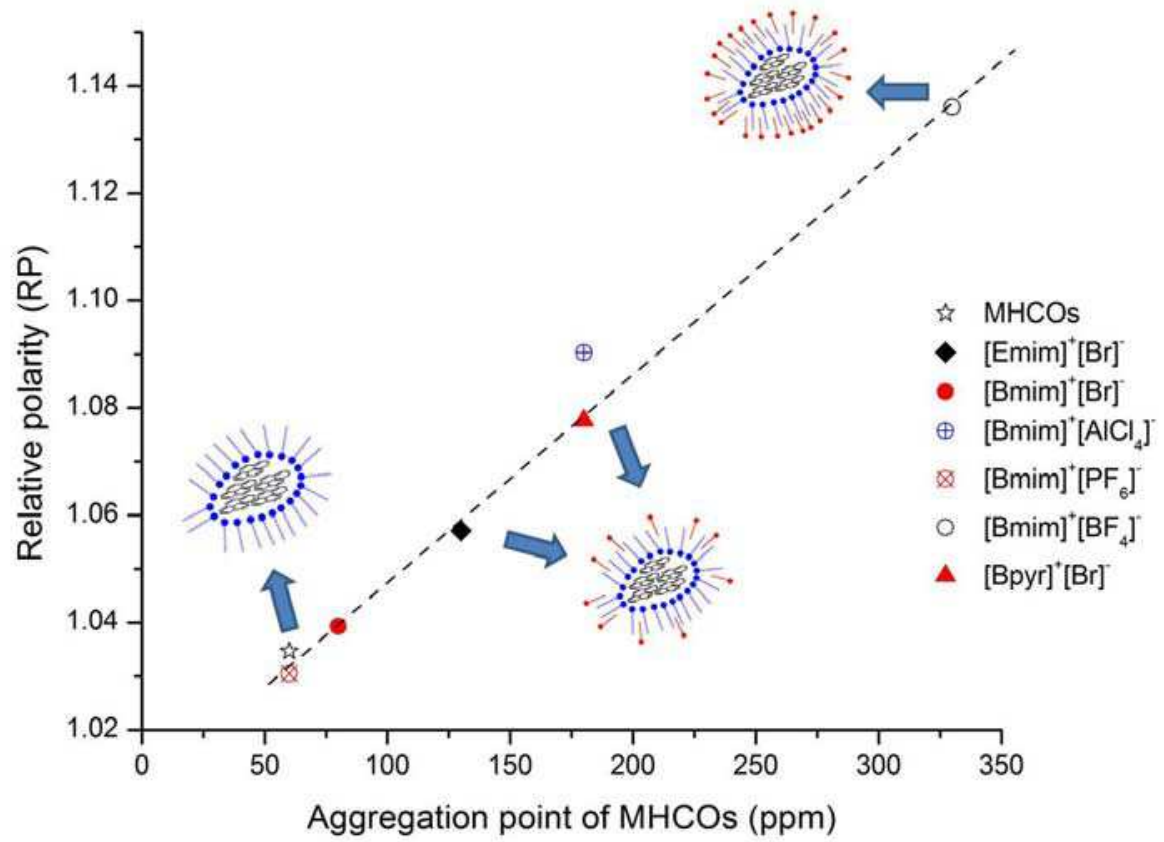

Fig. 7. The relative polarity set by different ILs on the aggregation point of MHCOs and proposed scheme for the interaction of ILs with resin-asphaltene aggregates. 


\subsection{Crude oil dehydration and desalting}

The fluids produced from mature wells are seldom pure crude oil and associated gas, and by far the most abundant material is formation or added water. The first is the water naturally located into the reservoir while the latter comes from production techniques to enhance crude oil recovery. Hence, secondary and tertiary oil recovery processes, some of which involve injecting water or steam into oil bearing formations, have become increasingly common, particularly in the production of heavy oil or bitumen (Sefton \& Sinton, 2010). Also, many wells produce large quantities of salt water, and safely disposing of it is a problematic and expensive problem. Additionally, brine may be corrosive and salts tend to precipitate through infrastructure (Speight, 1999). Also, salt-containing water can be present as a continuous or emulsionated phase (Figure 8) and must be separated as soon as possible from crude oil before its storage or refining. Nevertheless, the presence of very stable and tight water-in-oil (W/O) emulsions is a costly problem, resulting in high viscosity, the demand of expensive chemical products, corrosion and equipment with inefficient separations. The crude oil market demands that water in crudes must be removed to a level of less than $0.5 \%$ BSW (bottom, solids, water). Therefore, different physicochemical methods have been used to separate water from oil (Fan et al., 2009).

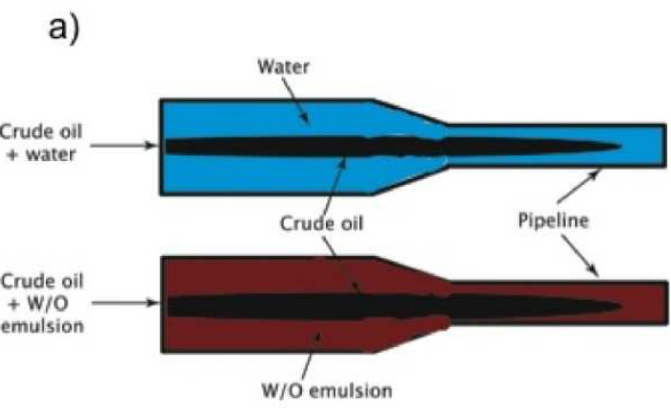

b)

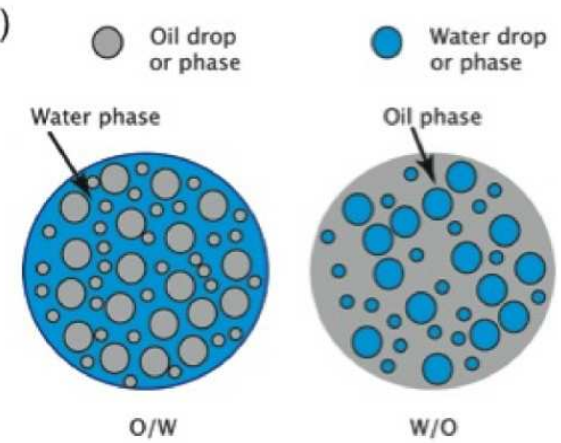

Fig. 8. Scheme for crude oil production with a) continuous and emulsionated water; and b) kinds of emulsions.

The stabilization of the W/O emulsion is mainly attributed to the formation of a rigid interfacial film of asphaltenes, where asphaltenes may accumulate as nanosized aggregates at the $\mathrm{W} / \mathrm{O}$ interface and have interplay with resins as a solubilizing agent (Sjöblom et al., 2001). W/O emulsions are complex multicomponent, multiphase systems. The effective viscosity of these mixtures is a function of many parameters such as the presence of solids, the presence of emulsifiers, the viscosity of individual phases, the droplet size and distribution, the density of constituents, the age of the emulsion, the shear rate at which the viscosity is sampled, the volume fraction of constituents and the temperature of the emulsion (Farah et al., 2005; Sefton \& Sinton, 2010). Hence, crude oil demulsification can be very difficult, non-efficient and it may require high residence times. Therefore, it is still one of the most frequently studied subjects in order to find efficient industrial methods to easily and economically break emulsions and desalts crude oil (Xu et al., 2006).

The self-organization, micelle formation and surface properties of ionic liquids (Luczak et al., 2008) as well as their use to dehydrate and desalt crude oil have been just recently reported (Guzmán-Lucero et al., 2010; Lemos et al., 2010). These research groups work on the 
demulsification of water-in-medium, heavy and extra-heavy crude oil emulsions assisted by conventional and microwave assisted heating. The latter technology has been known since 1978 and it accelerates the resolution of W/O emulsions as discussed elsewhere (Klaika, 1978; Fortuny et al., 2007). The microwave technology allows for the fast heating of emulsions, favouring the separation of crude oil emulsions into water and oil phases by thermal effects. The latter can be enhanced through the use of specific compounds with high dielectric properties, i.e. that augments the absorption of radiation by the sample and allows for the quicker resolution of the emulsion. Moreover, these additives can not only act in the heating system but also in the mechanisms involved in the process like modification of the interfacial tension between water and oil phases (Lemos et al., 2010). In this direction, ILs have been assayed as additives in the resolution of $\mathrm{W} / \mathrm{O}$ emulsions together with crude oil desalting. Several ILs with $[\mathrm{Br}]^{-},[\mathrm{Cl}]^{-},\left[\mathrm{PF}_{6}\right]^{-}$and $\left[\mathrm{BF}_{4}\right]^{-}$anions were tested on the emulsion rupture using the conventional and microwave-assisted bottle test. It was found that oil microwave-assisted demulsification with ILs depends on ILs dosage and surface activity, W/O interfacial tension, salt content on water phase, the type of crude oil, and irradiation time. Interfacial tension of $\mathrm{W} / \mathrm{O}$ emulsion diminishes in presence of water soluble ILs, i.e. ILs molecules go to the W/O interphase and weak the interfacial film which allows a more enhanced emulsion rupture and phase separation when microwaves are applied (Lemos et. al., 2010). By the other side, ILs may break $\mathrm{W} / \mathrm{O}$ emulsions with different types of crude oils, being the faster and higher demulsification efficiency in the order medium $>$ heavy $>$ extra heavy crude oil. It seems to us that high viscosity on extra-heavy crude oils somehow limits the mobility and coalescence of water drops inside the oily matrix, which delays phase separation (Figure 9). Many factors may affect emulsion stability and rupture but relevant parameters that must be deeply study are crude oil viscosity, asphaltenes, paraffins, naphtenic acids, salt content, ILs' surface properties, interfacial phenomena, etc.; in order to assess emulsion breakage factibility.

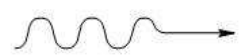

Microwave radiation

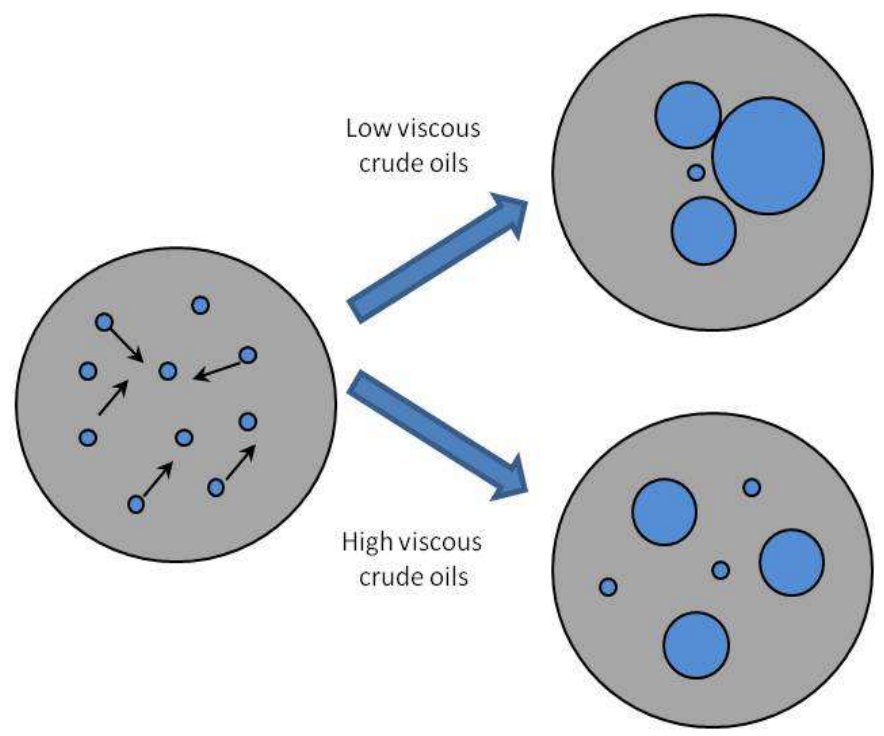

Fig. 9. Scheme for the mobility and coalescence of water drops in $\mathrm{W} / \mathrm{O}$ emulsions in low and high viscous crude oils under microwave-assisted deselmusification. 


\section{Petroleum refining}

Transportation fuel usage around the world is developing so fast because of their advantages of cost-efficiency and big power. However, SOx emissions are produced during fuel combustion, which brings environmental problems. Therefore, many stringent environment legislations have been issued to limit the sulphur (Esser et al., 2004) and aromatic content of fuels (EPA, 2008). There are two conventional desulfurization methods: hydrodesulfurization (HDS) and non-HDS. In the past few years, most of the sulfur was removed from the fuels through HDS in refineries. Nevertheless, the sulfur- and nitrogencontaining compounds left in fuels like gas oil and diesel after HDS are mainly aromatic compounds such as dibenzothiophene (DBT), carbazole and their alkyl derivatives (Figure 10). Hence, conventional HDS requires higher temperature under higher hydrogen pressures, which induces high operational costs and investments to get the lower sulfur content, reduce HDS catalyst deactivation and meet environmental regulations.

a)<smiles>c1ccc2c(c1)sc1ccccc12</smiles>

b)

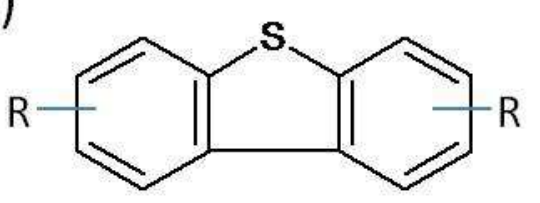

c)<smiles>c1ccsc1</smiles>

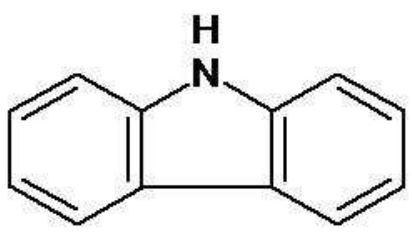<smiles>[R]c1ccc2[nH]c3ccc([R])cc3c2c1</smiles>

d)<smiles>c1ccncc1</smiles>

Fig. 10. Sulfur- and nitrogen-containing compounds usually found in hydrodesulfurized gas oil and diesel: a) dibenzothiophene, carbazole and b) their alkyl derivatives; and gasoline: c) thiophene and d) pyridine.

Room temperature ionic liquids (ILs) have been put in a wide range of application as green solvents for their low volatility and excellent thermal stability. In regard to the crude oil refining industry, the usage of ILs has been reported for desulfurization (Huang et al., 2004; Zhang et al., 2004; Mochizuki and Sugarawa, 2008; Xu et al., 2009; Wang et al., 2010), denitrogenation (Zhang et al., 2004; Huh et al., 2009) and dearomatization (Zhang et al., 
2004) of diesel and gasoline fuels as well as reduction of naphthenic acids in petroleum (Shi et al., 2008). In general, desulfurization, denitrogenation and dearomatization have been approached by mere extraction or extraction coupled with catalytic oxidation in ILs (Figure 11). Hence, sulfur removal by mere extraction with ILs displays low efficiencies (Huang et al., 2004). Here, the $\left[\mathrm{Cu}_{x} \mathrm{Cl}_{y}\right]^{-}$containing ILs could remove between $16-37 \%$ sulphur in gasoline and removal efficiency augments with the decreasing sulphur content. This was attributed to $\pi$-complexation of thiophene by $\mathrm{Cu}(\mathrm{I})$ as reported elsewhere (Hernandez and Yang, 2003). Another approach using a $\left[\mathrm{BF}_{4}\right]^{-}$-containing ILs found that sulphur and nitrogen removal slightly augmented with increasing heteroatom content in gasoline (Zhang et al., 2004). Moreover, an important removal of sulphur and aromatic compounds in gasoline occurs first by increasing the IL/fuel ratio and then by multiple extraction cycles with ILs. The aromatic removal, mainly benzene, is an attractive subject of study since the content of benzene cannot exceed $0.62 \%$ in gasoline from 2011 in the USA (EPA, 2008).

It is suggested that the main interaction between aromatic and sulphur, nitrogen-containing compounds and ILs and then the extraction mechanism occur with the $\pi$-electron density of aromatic compounds as it has been described elsewehere (Su et al., 2004; Gutel et al., 2009). Another approach uses $\left[\mathrm{SO}_{4}\right]^{-}$-based ILs to extract sulphur compounds in order to avoid the possible generation of $\mathrm{HF}$ and $\mathrm{HCl}$ during hydrolysis (Mochizuki and Sugarawa, 2008). They found a remarkable extraction of dibenzothiophene $(40-70 \%)$ in n-dodecane at an IL/model fuel ratio of 1:1 that increases with extraction time and steps as well as carbon number of ILs. The extraction efficiency of nitrogen-containing compounds increases with larger chain lengths of the alkyl groups in ILs and it was attributed to the increasing free volume left behind by bulky ILs (Huh et al., 2009). Here, the extraction of the basic quinoline may be facilitated by its coordination to the Zn center of ILs but the extraction of neutral indole is ruled by the interaction between the ILs' anion and the H-atom of the secondary amine group as shown by computational calculations.

Recently, Meindersma et al. (2010) have made a review of works dealing with dearomatization as well as some useful contributions. They state that activity coefficients are needed at finite dilutions for practical application and not at infinite dilution as most works present; the distribution coefficients must be calculated on a mass basis, and not mole, since this is the approach used in industry; the work results must be compared with conventional technologies as sulfolane extraction process; and whenever possible, a technical and economical estimation of the process must be done. In this regard, the aromatic/aliphatic selectivities with some ILs are 1.9 times higher when compared to sulfolane, while the investment cost may be reduced by a factor of two. Further research should take in mind the extraction mechanism between heteroatom-containing and aromatics compounds with ILs, removal efficiencies, ILs separation and recycling, use of solvents or cosolvents, applications for separated compounds, economical feasibility, etc. All latter approaches use biphasic extraction where surface area is poor, mass-transfer issues should be important and require a lot of ILs recycling steps. Recently, the use of ILs deposited on a solid, known as supported ionic liquid phase (SILP), incremented significantly the desulfurization efficiency by augmenting surface area, diminishing mass-transfer problems and allowing a continuous process (Kuhlmann et al., 2009). Careful attention must be paid to ILs leaching or saturation during process, but ILs chemical bonding to support as well as ILs-support reactivation are subjects that must be further studied. 


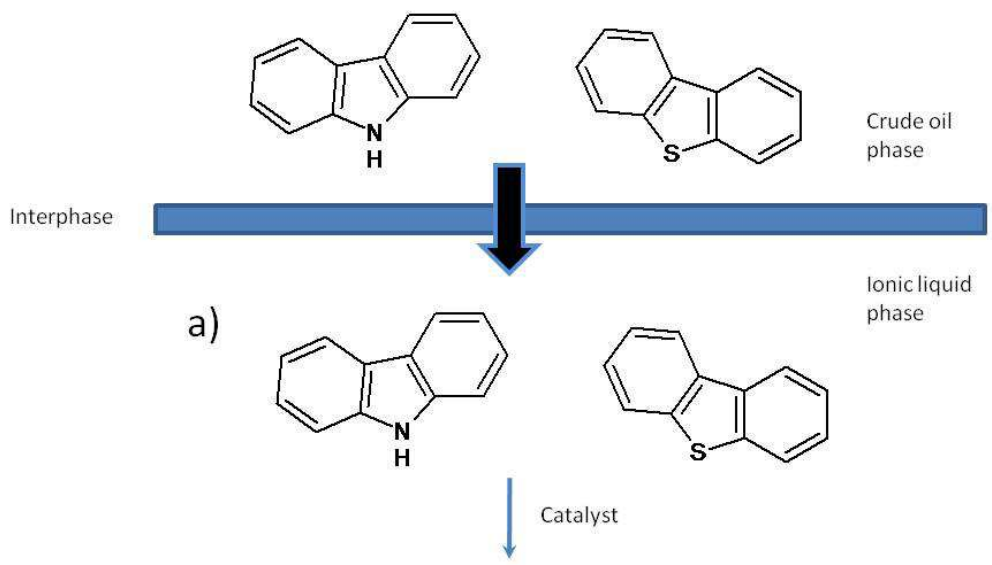

b)
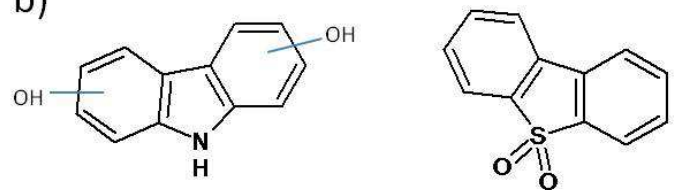

Fig. 11. Scheme for desulfurization and denitrogenation using ILs by a) mere extraction or b) extraction coupled with catalytic oxidation.

Conventional refining processes, as HDS, are typical catalytic ones where it is common the use of supported metals as $\mathrm{Al}, \mathrm{Co}, \mathrm{Mo}, \mathrm{V}, \mathrm{Ti}$, etc., to enhance and accelerate fuel desulfurization and denitrogenation. Although, the process results in hydrogen sulfide and ammonia that need to be further treated ahead in Refinery to meet environmental emission regulations. Chemical oxidation in conjunction with ILs extraction can sharply increase, when compared to mere extraction, the removal of sulphur and nitrogen from automotive fuels without producing polluting gases that need to be recovered. For instance, Lo et al. (2003) reported that oxidative desulfurization with $\mathrm{H}_{2} \mathrm{O}_{2}$-acetic acid combined with waterimmiscible IL of 1-butyl-3-methylimidazolium hexafluorophosphate ([Bmim]-[PF6] $]^{+}$lead to a high oxidation conversion and extraction of sulphur compounds in model- and light oil but the process took several hours. Moreover, the oxidative desulfurization of fuels using acidic ionic liquids like [Hmim]-[BF$]^{+}$and $[\mathrm{Hnmp}]-\left[\mathrm{BF}_{4}\right]^{+}$with $\mathrm{H}_{2} \mathrm{O}_{2}$ showed that sulfur removal from the model oil could reach over $90 \%$ in less than 60 minutes (Lu et al., 2007; Zhao et al., 2007). The reaction time in HDS processes are expressed as LHSV (liquid hourly space velocity) and common values range for nafta are between 6 to 10 h-1. Here, the assays were carried out with a LHSV between 132.14 and $529 \mathrm{~h}^{-1}$, too highs for industrial application but we must consider that it is homogeneous versus conventional heterogeneous catalysis. It is clear here that we need also to standardize reaction criteria for mutual comprehension and set assays conditions near to practical applications. The $[\mathrm{Hnmp}]^{-}\left[\mathrm{BF}_{4}\right]^{+}$ could be recycled up to 7 times without a significant decrease in activity and up to 12 cycles with $99.5 \%$ of sulphur removal. Conventional HDS catalyst may be normally used for 10 years, ILs and their recycling should take this into account and economical analysis is crucial to understand the process feasibility using ILs. 
Recently, a deep desulfurization system using an extraction and catalytic oxidation desulfurization process and including $\mathrm{H}_{2} \mathrm{O}_{2}, \mathrm{~V}_{2} \mathrm{O}_{5}$, and $[\mathrm{Bmim}]-\left[\mathrm{BF}_{4}\right]^{+}$, under mild conditions, has been proved to be efficient (Xu et al., 2009). Such approach showed high sulfur removal, which was superior to mere extraction with IL and extractive oxidation without catalyst. The advantages of using the extractive and catalytic system containing $\mathrm{V}_{2} \mathrm{O}_{5}$ and $[\mathrm{Bmim}]-\left[\mathrm{BF}_{4}\right]^{+}$are that ILs can be recycled seven times without a significant decrease in activity, and is a simple, mild, and environmentally friendly approach for deep desulfurization. Another approach used ozone and hydrogen peroxide as oxidation catalyst and sulphur removal reached $100 \%$ between 50 and $80^{\circ} \mathrm{C}$ (Wang et al., 2010). Nevertheless, these approaches remain still far away from industrial application and more intensive research should be done in order to assay with real diesel or nafta streams, understand the catalysis and thermodynamics of reactions, recycling of sulphur-saturated ILs, finding applications for oxidized heteroatom-containing compounds, and scale up of the extractive and oxidative extraction processes.

Finally, the presence of naphthenic acids in crude oil during refining operations may cause operational issues, such as foaming during crude oil desalting or other operation units as well as carrying cations through the refining process that may cause catalyst deactivation (Shi et al., 2008). They undertook an innovative approach to solve such a problem by forming ILs from the reaction of naphthenic acids and imidazole derivatives directly into the crude oil matrix, that allow ILs separation from crude oil. Even if high removal of naphthenic acids, transformed to ILs, was accomplished between 30 to $60^{\circ} \mathrm{C}$; it is necessary the use of a cosolvent to facilitate phase separation. This approach requires a further separation process to obtain relatively pure ILs and regenerated cosolvent. Here, the approach is interesting but when applied directly to oil reservoir, forming in-situ ILs, may help to all described issues found along the production, extraction and refining of crude oils.

\section{Conclusion}

ILs have been successfully assayed for the production, transportation and refining of crude oil at lab scale. Nevertheless, their potential application on the field has still to be proven. Many issues have to be solved before ILs may be currently applied in the petroleum industry. The economical, technological and environmental feasibility of large scale production and utilization of ILs must be asserted before any petroleum company accepts their daily use. The effect of the presence of ILs in crude oil during production, transport and refining must be asserted in order to identify operational issues. Therefore, much work is necessary at pilot plant and field scale to identify and fix the possible operational issues, infrastructure dimension and ILs handling. Even if ILs have still to prove their safely utilization in daily and routinely petroleum operations, we believe that they have already open a crucial window to more safe, environmental-friendly and tailor-made solutions to the actual problems of the petroleum industry.

\section{References}

Aburto, J.; Mar-Juárez, E. \& Juárez-Soto, C. Transportation of Heavy and Extra Heavy Crude Oil by Pipeline: A Patent Review for Technological Options. Recent Patents on Chemical Engineering, Vol.2, No.2, (2009) 86-97. 
ASTM D 2007-03. Standard test method for characteristic groups in rubber extender and processing oils amd other petroleum-derived oils by the clays-gel absorption chromatographic method.

ASTM D 5853. Standard test method for pour point of crude oils. 2009.

Boukherissa M.; Mutelet, F.; Modarressi, A.; Dicko, A.; Dafri, D.; \& Rogalski, M. Ionic Liquids as Dispersants of Petroleum Asphaltenes. Energy \& Fuels, Vol. 23, (2009) 2557-2564.

Buenrostro-Gonzalez, E.; Espinoza-Peña, M.; Andersen, S. I. \& Lira-Galeana, C. Characterization of asphaltenes and resins from problematic mexican crude oils. Pet. Sci. Technol., Vol. 19, No.3-4, (2001) 299-316.

Carbognani, L.; Orea, M. \& Fonseca, F. Complex nature of separated solid phases from crude oils. Energy \& Fuels, Vol. 13, (1999) 351-358.

Castro, L.V. \& Vazquez, F. Fractionation and characterization of mexican crude oils. Energy E Fuels, Vol. 23:, (2009) 1603-1609.

Chang, C.L. \& Fogler, H.S. Stabilization of asphaltenes in aliphatic solvents using alkylbenzene-derived amphiphiles. 1. Effect of the chemical structure of amphiphiles on asphaltene stabilization. Langmuir, Vol. 10, No.6, (1994) 1749-1757.

Environmental protection Agency (EPA). Control of hazardous air pollutants from mobile sources: early credit technology requirement revision. Federal Register, 73(201), 61358-61363, 2008.

Esser, J.; Wasserscheid, P. \& Jess, A. Deep desulfurization or oil refinery streams by extraction with ionic liquids. Green Chem., Vol. 6, No. 7, (2004,) 316-322.

Fan, Y.; Simon, S.; Sjöblom, J. Chemical destabilization of crude oil emulsions: effect of nonionic surfactants as emulsion inhibitors. Energy \& Fuels, Vol. 23, (2009) 45754583.

Farah, M.A.; Oliveira, R.C.; Navaes-Caldas, J. \& Rajagopal, K. Viscosity of water-in-oil emulsions: variation of temperature and water volume fraction. Journal of Petroleum Science and Engineering, Vol.48, (2005) 169-184.

Fortuny, M.; Oliveira, C.B.; Melo, R.L.; Nele, M.; Coutinho, R.C. \& Santos, A.F. Effect of salinity, temperature, water content, and $\mathrm{pH}$ on the microwave demulsification of crude oils emulsions. Energy \& Fuels, Vol. 21, No.3, (2007) 1358-1364.

García-Cruz, I.; Martínez-Magadán, J.M.; Salcedo, R. \& Illas, F. Electronic structure properties of dibenzofurane and dibenzothiophene derivatives: Implications on asphaltene formation. Energy \& Fuels, Vol. 19, No.3, (2005) 998-1002.

González, G.; Neves, G.B.M.; Saraiva, S.M.; Lucas, E.F. \& dos Anjous de Sousa, M. Electrokinetic characterization of asphaltenes and the asphaltenes-resins interaction. Energy \& Fuels,Vol. 17, (2003) 879-886.

Goual, L. \& Firoozabadi, A. Measuring asphaltenes and resins, and dipole moments in petroleum fluids. AICHE Journal, Vol. 48, No.11, (2002) 2646-2663.

Gutel, T.; Santini, C.C.; Padua, A.A.H.; Fenet, B.; Chauvin, Y.; Conongia-Lopez, J.N.; Bayard, F.; Costa-Gomez, M.F. \& Pensado, A.S. Interaction between the p-system of toluene and the imidazolium ring of ionic liquids: a combined NMR and molecular simulation study. J. Phys. Chem B., Vol. 113, (2009) 170-177.

Guzmán-Lucero, D.; Flores, P.; Rojo, T. \& Martínez-Palou, R. Ionic liquids as demulsifiers of water-in-crude oil emulsions: study of the microwave effect. Energy $\mathcal{E}$ Fuels, Vol. 24, (2010), 3610-3615. 
Hansmeier, A.R.; Jongmans, M.; Meindersma, G.W. \& de Haan, A.B. LLE data for the ionic liquid 3-methyl- $N$-butyl pyridinium dicyanamide with several aromatic and aliphatic hydrocarbons. J. Chem. Thermodynamics, Vol.42, (2010) 484-490.

Hernandez-Maldonado, A.J. \& Yang, R.T. Desulfurization of liquid fuels by adsorption via $\pi$ complexation with $\mathrm{Cu}(\mathrm{I})-\mathrm{Y}$ and $\mathrm{Ag}-\mathrm{Y}$ zeolites. Industrial $\mathcal{E}$ Engineering Chemical Research. Vol. 42, No.1, (2003) 123-129.

$\mathrm{Hu}$, Y.F.; Li, S.; Chu, Y.P. \& Guo, T.M. Wax precipitation in three Chinese reservoir oils under carbon dioxide $\left(\mathrm{CO}_{2}\right)$ injection. Energy \& Fuels, Vol. 18, (2004) 1183-1186.

$\mathrm{Hu}$, Y. F. \& Guo T. M. Effect of the structure of ionic liquids and alkylbenzene-derived amphiphiles on the inhibition of asphaltene precipitation from $\mathrm{CO}_{2}$-injected reservoir oils. Langmuir, Vol. 21, (2005) 8168-8174.

Huang, C.P.; Chen, B.H.; Zhang, J.; Liu, Z.C. \& Li, Y.X. Desulfurization of gasoline by extraction with new ionic liquids. Energy \& Fuels, Vol. 18, (2004) 1862-1864.

Huh, E.S.; Zazybin, A.; Palgunadu, J.; Ahn, S.; Hong, J.; Kim, H.S.; Cheong, M. \& Ahn. Zncontaining ionic liquids for the extractive denitrogenation of a model oil: a mechanistic consideration. Energy \& Fuels, Vol. 23, 2009, 3032-3038.

Isea, A. Geological synthesis of the Orinoco oil belt, Eastern Venezuela.Journal of Petroleum Geology. Vol. 10, No.2, (1987) 135-148.

Klaika, W.J. Method and apparatus for controlling fluency of high viscosity hydrocarbon fluids. US Patent 4,067,683, (1978).

Kuhlmann, E.; Haumann, M; Jess, A.; Seeberger, A. \& Wasserscheid, P. Ionic liquids in refinery desulfurization: Comparison between biphasic and supported ionic liquid Phase suspension processes. ChemSusChem, Vol. 2, (2009) 969-977.

Lemos, R.C.B.; da Silva, E.B.; dos Santos, A.; Guimaraes, R.C.L.; Ferreira, B.M.S.; Guarnieri, R.A.; Dariva, C.; Franceschi, E.; Santos, A.F. \& Fortuny, M. Demulsification of water-incrude oil emulsions using ionic liquids and microwave irradiation. Energy E Fuels, Vol. 24, (2010), 4439-4444.

Leon, O.; Rogel, E.; Espidel, J. \& Torres, G. Asphaltene structural characterization, selfassociation, and stability behavior. Energy \& Fuels, Vol. 14, No.1, (2000) 6-10.

Liu, Y.; Hu, Y.; Wang, H.; Xu, Ch.; Ji, D.; Sun, Y. \& Guo, T. Ionic liquids : Novel solvents for petroleum asphaltenes. Chinese J. Chem. Eng., Vol. 13, No.4, (2005) 564-567.

Lo, W.H.; Yang, H.Y. \& Wei, G.T. One-pot desulfurization of light oils by chemical oxidation and solvent extraction with room temperature ionic liquids. Green Chem., Vol 5, (2003) 639-642.

Lu, L.; Cheng, S.F.; Gao, J.B.; Gao, G.H \& He, M. Y. Deep oxidative desulfurization of fuels catalyzed by ionic liquid in the presence of $\mathrm{H}_{2} \mathrm{O}_{2}$. Energy \& Fuels, Vol. 21, (2007) 383384.

Luczak, J.; Hupka, J.; Thörming, J. \& Jungnickel, C. Self-organization of imidazolium ionic liquids in aqueous solution. Colloids and Surfaces A : Physicochemical and Engineering Aspects, Vol. 329, (2008) 125-133.

Mansoori, G.A. Modeling of asphaltene and other heavy organic depositions. Journal of Petroleum Science and Engineering. Vol 17, No. 1-2, (1997) 101-111.

Meindersma, G.W.; Hansmeier, A.R. \& de Haan, A.B. Ionic liquids for aromatic extraction. Present status and future outlook. Ind. Eng. Chem. Res., Vol.49, No.16, (2010) 75307540 . 
Mendell, J.L. \& Jessen, F.W. Mechanism of inhibition of paraffin deposition in crude oil systems. SPE, (1970) 171-182.

Mochizuki, Y. \& Sugarawa, K. Removal of organic sulfur from hydrocarbon resources using ionic liquids. Energy \& Fuels, Vo. 72, (2008) 3303-3307.

Murgich,J.; Abanero, J. A. \& Strausz, O.P. Molecular recognition in aggregates formed by asphaltene and resin molecules from the Athabasca oil sand. Energy \& Fuels, 1999, Vol.13, No. 2, (1998) 278-286..

Murgich, J.; Rogel, E.; León, O. \& Isea, R.A molecular mechanics-density functional study of the adsorption of fragments of asphaltenes and resins on the surface of $\mathrm{Fe}_{2} \mathrm{O}_{3}$.Pet. Sci. Technol., Vol. 19, (2001) 437-455.

Murillo-Hernández, J.; García-Cruz, I.; López-Ramírez, S.; Durán-Valencia, C.; Domínguez, J.M. \& Aburto, J. Aggregation Behavior of Heavy Crude Oil-Ionic Liquid Solutions by Fluorescence Spectroscopy. Energy \& Fuels, Vol. 23, (2009) 4584-4592.

Oh, K. \& Deo, M.D. Effect of organic additives on the onset of asphaltene precipitation. Energy \& Fuels, Vol. 16, No.3, (2002), 694-699.

Oliveria, G.E.; Mansur, C.R.E.; Lucas, E.F.; González, G. \& de Souza, W.F. The effect of asphaltenes, naphtenic acids, and polymeric inhibitors on the pour point of paraffins solutions. Journal of Dispersion Science and Technology, Vol.28, (2007) 349356.

Pacheco-Sánchez, J.H.; Álvarez-Ramírez, F. \& Martínez-Magadán, J.M. Morphology of aggregated asphaltene structural models. Energy \& Fuels, Vol. 18, No.6, (2004) 16761686.

Painter, P.; Williams, P. \& Lupinsky, A. Recovery of bitumen from Utah tar sands using ionic liquids. Energy \& Fuels, Vol. 24, (2010a), 2172-2173.

Painter, P.; Williams, P. \& Mannebach, E. Recovery of bitumen from oil or tar sands using ionic liquids. Energy \& Fuels, Vol. 24, (2010b) 1094-1098.

Pereira, J.C.; López, I.; Salas, R.; Silva, F.; Fernández, C.; Urbina, C. \& López, J.C. Resins : the molecules responsible for the stability/instability phenomena of asphaltenes. Energy \& Fuels, Vol. 21, (2007) 1317-1321.

Sedghi, M. \& Goual, L. Role of resins on asphaltene stability. Energy \& Fuels, Vol. 24, (2010) 2275-2280.

Sefton, E. \& Sinton, D. Evaluation of selected viscosity prediction models for water in bitumen emulsions. Journal of Petroleum Science and Engineering, Vol.72, (2010) 128133.

Shi, L.J.; Shen, B.X. \& Wang, G.Q. Removal of naphthenic acids from Beijiang crude oil by forming ionic liquids. Energy \& Fuels, Vol. 22, (2008) 4177-4181.

Sjöblom J.; Johnsen, E.E.; Westvik, A.; Ese, M.H.; Djuve J.; Auflem, I.H. \& Kallevik, H. Demulsifiers in the oil industry. In: Encyclopedic Handbook of Emulsion Technology. Sjöblom J. (Ed)., Marcel Dekker, New York, 2001, p. 595-619.

Speight, J. G. (1999). The Chemistry and Technology of Petroleum, Marcel Dekker Inc., New York.

Speight, J.G. Petroleum asphaltenes. Part 1: Asphaltenes, resins and the structure of petroleum. Oil and Gas Science and Technology- Rev. IFP, Vol.59, No.5, (2004a) 467477. 
Speight, J.G. Petroleum asphaltenes. Part 2: The effect of asphaltenes and resin constituents on recovery and refining processes. Oil and Gas Science and Technology-Rev. IFP, Vol.59, No.5, (2004b) 479-488.

Srivastava, S.P.; Butz, T.; Tiwari, G.B.; Oschmann, H.-J.; Rahimian, I. \& Phatak, S.D. Gel formation in vaccum gas oil. I. Role of composition. Petroleum Science and Technology, Vol. 20, No.3 \& 4, (2002) 269-290.

Strausz, O.P.; Morales-Izquierdo, A.; Kazmi, N.; Montgomery, D.S.; Payzant, J.D.; Safarik, I. \& Murgich, J. Chemical composition of Athabasca Bitumen: The saturate fraction. Energy \& Fuels, DOI: 10.1021/ef100702j

Su, B.M.; Zhang, S. \& Zhang, Z.C. Structural elucidation of thiophene interaction with ionic liquids by multinuclear NMR spectroscopy. J. Phys. Chem. B., Vol. 108, (2004) 1951019517.

Riveros, L.; Jaimes, B.; Ranaudo, M.A.; Castillo, J. \& Chirinos J. Determination of asphaltene and resin content in Venezuelan crude oils by using fluorescence spectroscopy and partial least squares. Energy \& Fuels, Vol. 20, (2006) 227-230.

Thanh, N.X.; Hsieh, M. \& Philp, R.P. Waxes and asphaltenes in crude oils. Organic Geochemistry. Vol. 30, (1999) 1119-132.

Visintin, R.F.G.; Lockhart, T.P.; Lapasin, R. \& D'Antona, P. Structure of waxy crude oil emulsion gels. Journal of Non-Newtonian Fluid Mechanics, Vol.149, (2008) 34-39.

$\mathrm{Xu}$, X.; Yang, J.; Jiang, Y. \& Gao, J. Effects of process conditions on desalting and demetalization of crude oil. Petroleum Science and Technology, Vol. 24, (2006) 13071321.

Xu, D.; Zhu, W.; Li, H.; Zhang, J.; Zou, F.; Shi, H. \& Yan, Y. Oxidative desulfurization of fuels catalyzed by $\mathrm{V}_{2} \mathrm{O}_{5}$ in ionic liquids at room temperature. Energy $\mathcal{E}$ Fuels, Vol. 23, (2009) 5929-5933.

Wang, J.; Zhao, D. \& Li, K. Oxidative desulfurization of dibenzothiophene using ozone and hydrogen peroxide in ionic liquid. Energy \& Fuels, Vol. 24, (2010) 2527-2529.

Zhao, D.S.; Wang, J. L. \& Zhou, E.P. Oxidative desulfurization of diesel fuel using a Brønsted acid room temperature ionic liquid in the presence of $\mathrm{H}_{2} \mathrm{O}_{2}$. Green Chem., Vol. 9, (2007) 1219-1222.

Zhang, S.; Zhang, Q. \& Zhang, Z.C. Extractive desulfurization and denitrogenation of fuels using ionic liquids. Ind. Eng. Chem. Res, Vol.43, (2004) 614-622.

Zhang, S. \& Huang, H. Geochemistry of palaeozoic marine petroleum from the Tarim basin, NW China: parti. Oil family classification. Organic Geochemistry, Vol.36, (2005) 1204-1214. 


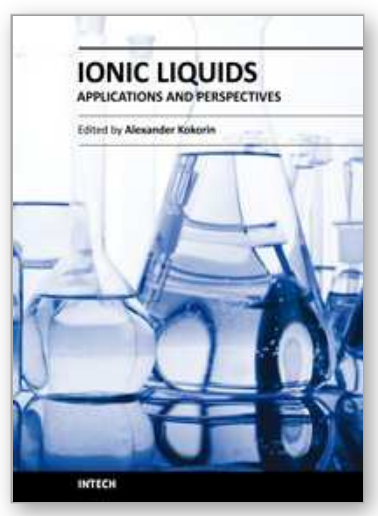

\author{
Ionic Liquids: Applications and Perspectives \\ Edited by Prof. Alexander Kokorin
}

ISBN 978-953-307-248-7

Hard cover, 674 pages

Publisher InTech

Published online 21, February, 2011

Published in print edition February, 2011

This book is the second in the series of publications in this field by this publisher, and contains a number of latest research developments on ionic liquids (ILs). This promising new area has received a lot of attention during the last 20 years. Readers will find 30 chapters collected in 6 sections on recent applications of ILs in polymer sciences, material chemistry, catalysis, nanotechnology, biotechnology and electrochemical applications. The authors of each chapter are scientists and technologists from different countries with strong expertise in their respective fields. You will be able to perceive a trend analysis and examine recent developments in different areas of ILs chemistry and technologies. The book should help in systematization of knowledges in ILs science, creation of new approaches in this field and further promotion of ILs technologies for the future.

\title{
How to reference
}

In order to correctly reference this scholarly work, feel free to copy and paste the following:

Murillo-Hernández José-Alberto and Aburto Jorge (2011). Current Knowledge and Potential Applications of Ionic Liquids in the Petroleum Industry, Ionic Liquids: Applications and Perspectives, Prof. Alexander Kokorin (Ed.), ISBN: 978-953-307-248-7, InTech, Available from: http://www.intechopen.com/books/ionic-liquidsapplications-and-perspectives/current-knowledge-and-potential-applications-of-ionic-liquids-in-the-petroleumindustry

\section{INTECH}

open science | open minds

\author{
InTech Europe \\ University Campus STeP Ri \\ Slavka Krautzeka 83/A \\ 51000 Rijeka, Croatia \\ Phone: +385 (51) 770447 \\ Fax: +385 (51) 686166 \\ www.intechopen.com
}

\author{
InTech China \\ Unit 405, Office Block, Hotel Equatorial Shanghai \\ No.65, Yan An Road (West), Shanghai, 200040, China \\ 中国上海市延安西路65号上海国际贵都大饭店办公楼 405 单元 \\ Phone: +86-21-62489820 \\ Fax: $+86-21-62489821$
}


(C) 2011 The Author(s). Licensee IntechOpen. This chapter is distributed under the terms of the Creative Commons Attribution-NonCommercialShareAlike-3.0 License, which permits use, distribution and reproduction for non-commercial purposes, provided the original is properly cited and derivative works building on this content are distributed under the same license. 